\title{
ANP APPLICATION IN OBSTETRICS: EVALUATING NORMAL DELIVERY AND CESAREAN DELIVERY USING BOCR ANALYSIS
}

\author{
Eranjan U. Padumadasa* \\ Asia Pacific Institute of Information Technology \\ Colo mbo, Sri Lanka \\ E-mail: eranjan@apiit.lk \\ Nuwan S. Padumadasa \\ Faculty of Medicine, University of Colo mbo \\ Colo mbo, Sri Lanka \\ E-mail: nuwan.saa@gmail.com
}

\begin{abstract}
Current reproductive health statistics in Sri Lanka shows a rise in the rate of caesarean delivery rate; consistent with other countries. However, according to the Forteles a declaration drown by the WHO states that the rate of caesarean deliveries should be kept within a range of $10-15 \%$. Nevertheless, more and more expecting mothers opt for the caesarean sections looking at the short term benefits it yields. This research aimed to structure the decision making involved and to identify the best method suited for delivery looking at Benefits, Costs and Risks. ANP was used as the methodology for this research, which revealed that Normal Delivery is more preferred at a rate of $72 \%$.
\end{abstract}

Keywords: Caesarean Delivery, Normal Delivery, Pregnancy, Obstetrics

\section{Introduction}

Giving birth to a physically and mentally healthy child is the most precious and memorable event in any woman's life. In early 1900 's, home delivery was in the forefront mainly due to the lack of medical facilities and expertise available, which has greatly changed, now and developed to an accomplishing venture. The decision of the model of delivery was not an issue some time ago but current data reveals that it has developed into a state of debate of selecting between the two main options: Normal Vaginal Delivery (NVD) or Caesarean Section (CS). Caesarean section was introduced in clinical practice as a lifesaving procedure both for the mother and the baby for specific indications. The current trend towards selecting Caesarean sections has increased to an extent resulting in a global epidemic in every part of the world. According to the Fortelesa Declaration by WHO in 1985 (Ho meb irth Network SA, 2011c), "the whole community should be informed about various procedures in birth care, to enable each woman to choose the type of birth care she prefers and also it clearly states that there is no justification in any specific geographic region to have more than 10 - $15 \%$ of caesarean section births".

As stated by Menacker (2005) and also considering the data provided by coalition for Maternity services (Motherfriendly Organization, 2010), also recommend a primary caesarean rate of 15\% or less. This recommendation of $15 \%$ is based on research indicating that, if a location's caesarean rates rise significantly above $15 \%$, morbidity and mortality may also begin to rise. During the past year, the task force on caesarean section rate of the American College of Obstetricians and Gynaecologis ts recommended a target for reducing the rate to $15 \%$ in the USA by year 2010 (Bergero, 2007). According to The Associated Press (2010), has shown the world's highest caesarean rate of $46 \%$ in china. And the same article states that, "the WHO, which reviewed nearly 110,000 births across Asia in 2007- 2008, found 27\% were done under knife, partially motivated by hospitals eager to make more money" ( The Associated Press, 2010). As stated by Hamilton, Martin, and Ventura (2010), the caesarean rate rose to $32.9 \%$ in United States in 2009 and it has been predicted that it will reach a higher significant numbers in the coming years. In Brazil, there are hospitals with $100 \%$ caesarean section rates, health districts with $85 \%$ rates and entire states' with $47.7 \%$ rates (Mukherjee, 2006).

The epidemic proportions of caesarean section in many countries in the world, have posed many social, cultural and financial problems. Many studies point out that caesarean sections has a higher risk of increasing maternal mortality rates, and other complications (Durham, 2010c; Mukherjee, 2006) where a fourfold increase in maternal mortality

\footnotetext{
* Corresponding author
} 
rate associated with caesarean sections were observed even after controlling for med ical and obstetric complications, maternal age and preterm delivery (Durham, 2010c; Mukherjee, 2006). They (Durham, 2010c; Mukherjee, 2006) further go on to say that, elective caesarean sections have a 2.84 fold greater chance of maternal death as compared to vaginal birth. This epidemic is not only a current issue but also would generate a negative impact on fertility as a complication in the future.

\subsection{Sri Lankan Context}

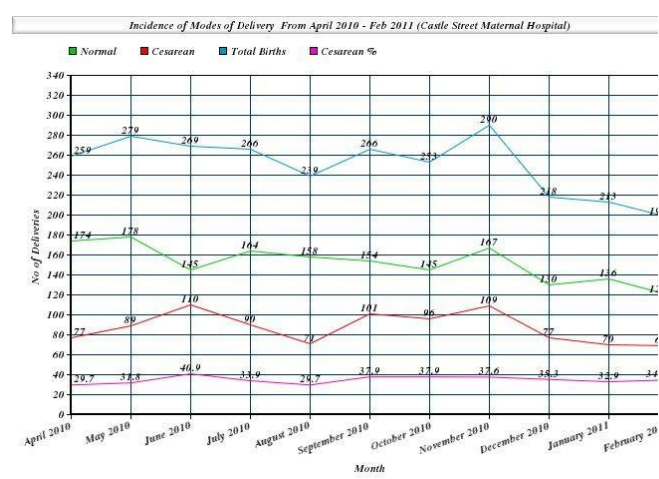

Figure 1: Caesarean Sections vs. Normal Delivery
The circumstances in Sri Lanka do not differ to what is seen in any other part of the world. According to The Sunday Observer (Sunday Observer, 2007) "the current caesarean rate has increased by $30 \%$ compared to 10years ago according to ministry sources".

The rate of caesarean sections in government hospitals have increased from 9\% in 1986 to $14.4 \%$ in 1999 (Gunasekera, Wijesinghe, \& Goonewardene, 2001). Due to the absence of country wide up to date statistics, data was collected from a cohort from one of the leading maternity hospital in Sri Lanka: Castel Street Maternal Hospital. It shows an average current rate of $34.8 \%$ for caesarean sections. Caesarean section rate has gradually increased from $29.7 \%$ in 2010 April to $34.8 \%$ in 2011 February. Even with fluctuations, the general trend of Normal vaginal delivery has dropped from $67.2 \%$ in 2010 April to $60.6 \%$ in February 2011. So, this data clearly signifies the contribution of Sri Lanka to the ongoing caesarean epidemic which deserves serious attention.

\subsection{Significance of Research}

One of the most important reasons contributing to the problem is Caesarean section on maternal request and present which is supported by epidemiological data. In Sri Lanka the gender ratio in the current population is estimated to be 97.5 males to 100 females. The sex ratio skewed in favour of females is largely attributed to the higher life expectancy of women (Central Inteligence Agency, 2011). There is also a rising trend of literacy among women which is supported by the adult female literacy rate of 87 in 2000 to 90 in 2009 (United Nations Population Fund Sri Lanka, 2009). So this shows that at present and also in the future we will be dealing with a literate female population who are wise enough to demand their needs in all aspects of life, especially the choice of delivery.

An analysis conducted suggests, a "strong inverse association between caesarean section rates and maternal, infant and neonatal mortality in countries with high mortality levels. There is some suggestion of a direct positive association at lower levels of mortality" ( Betrán, et al., 2007). "Maternal mortality is 2-4 times higher and morbidity is 5-10 times higher after a caesarean compared to vaginal birth" (Shearer, 1993). Sri Lanka has an $11.9 / 10^{6}$ (Department of Census and Statistics - Sri Lanka, 2010) live births which are regarded as significantly low compared to other countries in the region. So the addition of maternal deaths might be a result of the rise in caesarean section rate.

Sri Lanka being a developing nation, with high resource constrains would benefit from the outcome of this research on the decision making in the mode of delivery, permit optimizing various resources in labour rooms to help identify wo men, who can be diverted to peripheral health care centres run by midwives and primary care physicians, sparing tertiary and specialist care for deserving minority.

\section{Literature Review}

Even though it seems a simple matter to the lay person, decision making for the proper mode of delivery requires expert knowledge and skills in order to cater the individual need. The decision is made in collaboration of three criteria which are Technical require ments, maternal request and state of current pregnancy.

Spaeth (2010) states that, "many points (31\%) to cesarean section on maternal request (CSMR) as the prime reason the higher rate". As defined in the first principle of medical ethics; Autonomy; every woman has a right to choose the treatment modality and agree or disagree to what has been chosen for her. CS births have not been proven to be of any benefit to mother or child in uncomplicated pregnancies. Therefore, a physician may be violating the principles of beneficence and non-malfeasance when agreeing to CSMR by putting mother and child at unnecessary 
risk of harm (Spaeth, 2010). So decision should be made weighing the medical ethical principles of autonomy with beneficence and non-malfeasance. Guidelines from The National Institute for Clinical Excellence on Caesarean section recommend that "maternal request is not on its own an indication for Caesarean section," and that "a clinician can decline such a request" (NICE, 2004; Ugwu madu, 2005). Level of sophistication which includes: level of education, employment, socioeconomic status and age; is one factor which is playing a role in maternal request for a particular mode of delivery.

According to Khan and Zaman (2010), the higher education is directly as sociated with CS. Supporting the previous claim, Gilbert, Benjamin, and Abenhaim (2010) states that, higher education appears to be associated with an increased rate of elective repeat Caesarean sections. But on the contrary according to, Tollånes, Thompson, Daltveit and Irgens (2007) identified that the lowest educated had the highest risk of CS. This might be due to the fact that the study group was easily influenced by different sources. Cesarean rates are influenced by non-medical factors. That is the rates are higher for older, married, educated, women who have private medical insurance, who are private rather than public clinic patients, who belong to a higher socio-economic bracket (Childbirth Organization, $\mathrm{ND}$ ). Other sub criteria of maternal choice are source of influence: family me mbers, associates, media and medical professionals, Level of anxiety due to expected pain, previous negative experiences heard either with the birth process itself or with hospital care and finally culture and beliefs the mother entitles to. So me of the common beliefs mothers have are "once a cesarean always a cesarean" (Ugwumadu, 2005), elective Caesarean is a very safe procedure, with almost no risk whatsoever ( Siddal, Street, Ablet, Selinger, \& Allott, 2005), Caesareans are better for the baby and that a section will prevent the mother from developing a prolapse in middle age ( Siddal, Street, Ablet, Selinger, \& Allott, 2005), "normal delivery should be attempted or she will not get the natural experience of birth" etc.. In India and china, the families "sometimes demands that the baby be born on an auspicious/ astrological calculation which is possible only with elective cesarean sections" (Mukherjee, 2006). Most of the women "like to maintain the vaginal tone of teenagers but this is actually a benefit to her partner rather than to herself" (Mukherjee, 2006). Informed maternal choice: decision made after adequate evidence based information had been provided to the mother; is much superior to maternal choice persuaded by the clinician. "Inadequately informed wo men choose CS to avoid painful natural birth" (Mukherjee, 2006). Obstetricians are a strong source influencing maternal choice of the mode. Obstetrician's preference lies on experience and practice, skill availability, financial gain, personal preference: fear of perineal injuries, incontinence and fetal injury, convenience and control over procedure; and defensive medical practices.

A technical requirement for either normal vaginal delivery or CS is another factor which should be considered when deciding on a mode for delivery. Its sub criteria include resource availability: labour room equipment, theater facilities etc.; medical expertise for decision making and carrying out the procedure and finally skill availability for performing normal vaginal deliveries, cesarean section and most importantly art of instrumental vaginal deliveries.

The most important factor for decision making for mode of delivery on the part of the obstetrician or health care professional is the state of the current pregnancy. The data collected and observations seen from the booking visit: first visit to the anti-natal clin ic, itself is taken in to consideration in the process of decision making. The sub criteria are maternal features include: height, pre-pregnant weight/ BMI; gestation, weight gain/ increase in BMI during pregnancy: the number of weeks for the current pregnancy, no of fetuses, fetal presentation: head, breech or shoulder; past sections and finally comorbidities and maternal infections: Pregnancy induced hypertension, preeclampsia, gestational diabetes mellitus, herpes, HIV etc. Although gestation, no of fetuses, presentation and, Comorbidities and maternal infections are part of maternal features it was decided to consider as separate subcriteria due to its importance perceived by many doctors. According to Randolph, Washington and Prober (1993) Women who present with their first clinical episode of genital Herpes at delivery should have a cesarean section performed. Women who have an uncomplicated singleton breech pregnancy at 36 weeks gestation should be offered external cephalic version but in instances where external cephalic version is contraindicated or failed should be offered a CS according to the NICE guidelines for CS (NICE, 2004).The A merican College of Obstetrics and Gynaecology has published a practical guide in summarizing the evidence supporting Vaginal Birth after Cesarean (VBAC) as the preferred method of delivery after one previous CS and a possible method of delivery after two or more CS although we cannot advocate or proclaim that VBAC is safer after two previous CS (Bergero, 2007) .In 2003, the Ethics committee of American College of Obstetricians released a statement that "if a physician believes that cesarean delivery promotes the overall health and welfare of the woman and her fetus...then he or she is ethically justified in performing a cesarean delivery" (Bergero, 2007). Literature review further revealed that NVD has fewer complications ( BUHIMSCHI \& BUHIMSCHI, 2006), less cost and higher maternal participation as benefits. Benefits were also revealed for CS as, the less time and more access to future interventions. In terms of the costs or short term losses for both NVD and CS were identified as; excessive haemorrhage, hospitalization, infections, pain, 
psychological is sues, short term complications, trau matic in juries. In terms of Risks or long term losses the literature review yielded; cosmetic outcomes, long term complications, poor obstetrics outcomes, Death/mortality. 


\section{Proposed ANP Model and Results}

As stated above, this research used Analytical Network Process (ANP) as the methodology for its evaluation. ANP is considered a relatively new methodology in the field of research (Shang, Tjader, \& Ding, 2004), which is gaining popularity in the international research domain. However, in terms of research carried out in Sri Lanka, it is worthy tomention that there are no published researches using this methodology. As stated by Saaty and Ozdemir (2005) ANP "is a generalization of the Analytical Hierarchy Process". Both AHP as well as ANP are used as decision support tools to provide assistance to decision makers taking in to account various as pects, from various view points. As explained by Saaty and Ozdemir (2005), many problems cannot be structured hierarchically as they could include interactions and dependencies of higher level elements in a hierarchy on lower level ele ments.

The first step in ANP decision model involves; identification, selection, analysis, and categorization of decision criteria involved with the problem. Based on this the goal was defined along with the relevant strategic criteria. As identified by Saaty (2010) Strategic criteria are objectives or criteria which the decision maker needs to always consider in making the decision. The other criteria identified through the literature review, were further analyzed and grouped in to Benefits, Costs, Opportunities, and Risks or in other words according to the BOCR framework identified by Saaty (2010).Following diagram outlines how these criteria were grouped as Benefits, Opportunities, Costs, \& Risks.

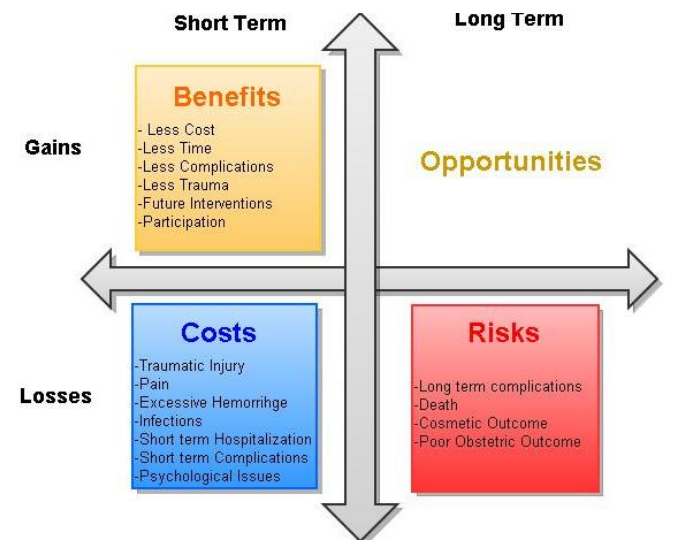

Figure 2. BOCR Criteria Categorization
A questionnaire based on the model was drafted and was distributed to five doctors who practice at the Castel Street Maternal Hospital. The method of sampling selected was convenience based sampling as it is not practical to sample doctors as they are constantly on duty. Although this is a nonrandom sampling method, the results could be generalized to define the response of the entire population of obstetricians. As explained by Shang, Tjader, and Ding (2004) implementation of ANP within a group requires aggregating the preference of the different individuals in to a consensus rating.

The
method
adopted
for this

purpose is the use of geometric mean. However, for the purpose of rating, the panel took a consensus vote. The three subnets used in the above stated ANP model is illustrated in Figure 3. Benefits subnet details the advantages of the delivery methods in general and are compared based on the two alternatives. As illustrated the comparison was done both ways; i.e. the respective benefits of each alternatives were compared with each other; at the same time, each advantage was compared

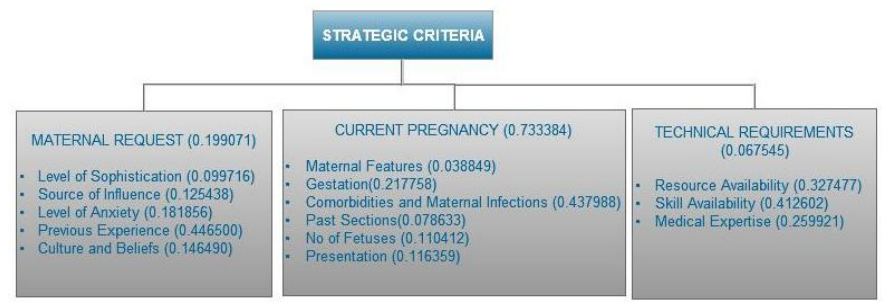

Figure 4. Strategic Criteria used in the ANP Model

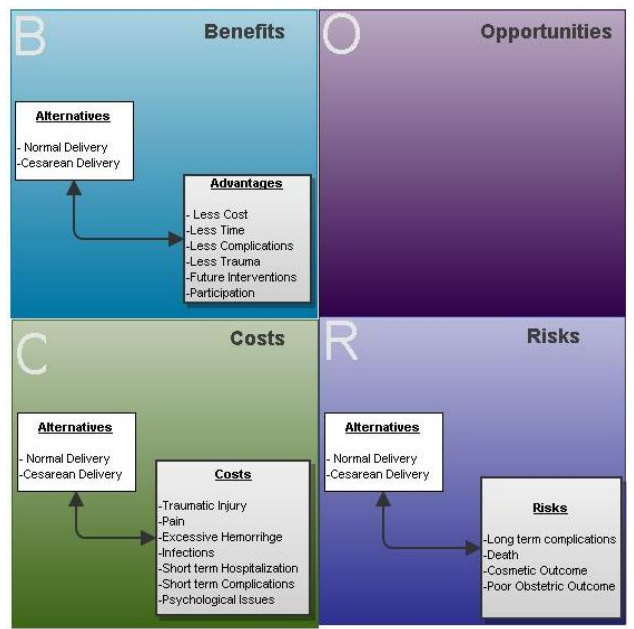

Figure 3. BOCR Subnets

between the two alternatives to see which one would more likely to contain it.

This was done with the costs as well as the risks. However, some costs and risks were limited to only one alternative. Opportunities were not considered in the models with the discretion of the panel of doctors as they 
identified that most gains are rather short term than long term, hence these were categorized and compared under Benefits subnet.

The strategic criteria were also compared with each other against the goal. The sub strategic criteria were also compared with each other in order to identify the relative importance of each of the sub strategic criteria. Figure 4 identifies the strategic criteria and its sub criteria with its respective weights after the pair wised comparison.

The complete list of criteria and its elements with its local and global weights are listed in Table 3. A careful analysis of the synthesized results of the model made it clear that some criteria did not contribute much to the overall priority weighting of the two alternatives. According to Shang, Tjader, \& Ding (2004) only the criteria whose global weight is more than 0.025 significantly contribute to the ranking of the alternatives. Except for the Level of Sophistication, Resource Availability and Medical Expertise, all the other strategic criteria significantly contribute to the ranking of alternatives. The Benefits of Less Trauma and Risk of poor obstetrics outcomes were also seen to be less significant. As adviced by Saaty (2001 cited Shang, Tjader, \& Ding, 2004) the less significant criteria should be removed from model to improve the validity of the model. However, the simplified model yeilded similar results as the recommended full model. It was decided to include the less significant criteria eventhough it yeilds similar results. The strategic criteria were then rated using the following rating model.

Very Strong $(\mathrm{VS})=1.00 \mid$ Strong $(\mathrm{S})=0.63 \mid$ Medium $(\mathrm{M})=0.38 \mid$ Moderate $(\mathrm{MO})=0.23 \mid$ Weak $(\mathrm{W})=0.15$

Table 1. Strategic Criteria and BOCR Priorities

\begin{tabular}{|c|c|c|c|c|c|c|c|c|c|c|c|c|c|c|c|}
\hline & LOS & LOA & SOI & PE & CAB & SA & RA & ME & MF & G & CAMI & PS & NF & P & Priorities \\
\hline Benefits & W & S & S & W & S & S & S & S & S & S & W & MO & M & VS & 0.409669 \\
\hline Costs & S & S & S & S & W & MO & MO & MO & S & W & MO & W & MO & W & 0.290461 \\
\hline Risks & VS & M & S & M & S & MO & S & S & S & W & MO & W & MO & W & 0.299869 \\
\hline
\end{tabular}

Results of the rating show that the most important merit is Benefit at $40.9 \%$ followed by Risks at $29.9 \%$ and Cost at $29 \%$. The Benefits at $41 \%$ drives the decision more than the Costs at $29 \%$ due to the fact that, the priorities of alternatives under benefits are weighed heavily.

Table 2. Overall Outcome

\begin{tabular}{|l|c|c|c|c|c|}
\hline \multicolumn{1}{|c|}{ Alte rnatives } & Benefits : 0.4097 & Costs : 0.2905 & Risks :0.2999 & Outcome B/CR & Outcome bB + c(1-C) + r(1-R) \\
\hline Natural Vaginal Delivery & 0.63018 & 0.35581 & 0.42874 & 4.13097 & 0.616581 \\
\hline Caesarean Delivery & 0.36982 & 0.64419 & 0.57126 & 1.00495 & 0.383419 \\
\hline
\end{tabular}

\begin{tabular}{|c|c|c|c|c|}
\hline Name & Graphic & Ideals & Normals & Raw \\
\hline Cesarean Delivery & & 0.391224 & 0.281209 & 0.240410 \\
\hline Natural Yaginal Delivery & & 1.000000 & 0.718791 & 0.614508 \\
\hline
\end{tabular}

Figure 5. BOCR Model: Overall Synthesized Result from Super Decisions

The final results shown in Table 2 were obtained by using the additive probabilistic model $b B+c(1-C)+r(1-R)$. Irrespective of the method used to calculate the outcome Normal Delivery is scored at the best option. According to Saaty (2010, p.337) multiplicative synthesis identifies the most preferable alternative in the short run, whereas, the additive synthesis identifies the most preferable alternative in the long run. According to the results received, the alternative that is preferable in the long and short run is Normal Delivery.

Table 3. Clusters in the Decision Network and the Elements within the Clusters

\begin{tabular}{|c|c|c|c|c|}
\hline Strategic Criteria & Sub Criteria & Elements & $\begin{array}{c}\text { Local } \\
\text { Priorities }\end{array}$ & $\begin{array}{c}\text { Global } \\
\text { Priorities }\end{array}$ \\
\hline \multirow{5}{*}{$\begin{array}{l}\text { Maternal } \\
\text { Request } \\
(0.199071)\end{array}$} & Level of Sophistication (LOS) & Education level, Occupation, Age, Access to information & 0.099716 & 0.019850 \\
\hline & Level of Anxiety (LOA) & Perceived pain, previous negative experiences heard & 0.181856 & 0.036202 \\
\hline & Source of In fluence (SOI) & Family Members, Associates, Media, Medical Professionals & 0.125438 & 0.024971 \\
\hline & Previous Experience (PE) & Past experience giving birth, Stories of birth & 0.446500 & 0.088886 \\
\hline & Culture and Beliefs (CAB) & $\begin{array}{l}\text { Once a caesarean always a caesarean, Elective Caesarean is very } \\
\text { safe procedure, Caesareans are better for the baby, A section to } \\
\text { avoid prolapse, normal delivery only natural experience of birth }\end{array}$ & 0.146490 & 0.029162 \\
\hline \multirow{3}{*}{$\begin{array}{l}\text { Technical } \\
\text { Requirements } \\
(0.067545)\end{array}$} & Skill Availability (SA) & Instrumental deliveries, External Cephalic Version & 0.412602 & 0.027870 \\
\hline & Resource Availability (RA) & Drugs, Anaesthesia, Surgical Tools & 0.327477 & 0.022120 \\
\hline & Medical Expertise (ME) & Skilled medical professionals & 0.259921 & 0.017556 \\
\hline \multirow{5}{*}{$\begin{array}{l}\text { Current } \\
\text { Pregnancy } \\
(0.733384)\end{array}$} & Maternal features (MF) & $\begin{array}{l}\text { Height, Pre-pregnant Weight or BMI, Weight gain/ increase in BMI } \\
\text { during pregnancy }\end{array}$ & 0.038849 & 0.028492 \\
\hline & Gestation $(\mathrm{G})$ & No of weeks of the current pregnancy & 0.217758 & 0.159700 \\
\hline & $\begin{array}{l}\text { Comorbidities and Maternal Infections } \\
\text { (CAMI) }\end{array}$ & $\begin{array}{l}\text { Pregnancy induced hypertension, Pre-eclampsia, Gestational } \\
\text { diabetes mellitus, Herpes, HIV }\end{array}$ & 0.437988 & 0.321213 \\
\hline & Past Sections (PS) & Past caesarean sections & 0.078633 & 0.058766 \\
\hline & No of Fetuses (NF) & No ofbabies expecting & 0.110412 & 0.080974 \\
\hline BOCR & Clusters & Elements & \multicolumn{2}{|c|}{ Local Priorities } \\
\hline Benefits & Time & Less time & \multicolumn{2}{|c|}{0.24654} \\
\hline
\end{tabular}




\begin{tabular}{|c|c|c|c|}
\hline \multirow[t]{5}{*}{$(0.398428)$} & Cost & Less cost & 0.12604 \\
\hline & Complications & Less complications & $\mathbf{0 . 3 7 8 1 1}$ \\
\hline & Trau ma & Less amount of trau ma & 0.00000 \\
\hline & Future Interventions & Permanent sterilization such as LRT, E mergency Hysterectomy & $\mathbf{0 . 1 2 3 2 7}$ \\
\hline & Maternal Participation & Avoid feeling of inadequacy, guilt and failure, Improve bonding & $\overline{0.12604}$ \\
\hline \multirow[t]{7}{*}{$\begin{array}{l}\text { Costs } \\
(0.282491)\end{array}$} & Trau matic Injuries & $\begin{array}{l}\text { Perineal tears, Fetal laceration, fractured clavicle, brachial plexus, } \\
\text { intracranial haemorrhages }\end{array}$ & $\overline{0.04988}$ \\
\hline & Pain & Perceived pain and actual pain & $\overline{0.16374}$ \\
\hline & Excessive Haemorrhage & Post partumhaemorrhage & $\overline{0.20359}$ \\
\hline & Infections & Pelvic inflammatory disease, Hospital acquired, surgical site & $\overline{0.14445}$ \\
\hline & Hospitalization & Short termhospitalization & 0.16175 \\
\hline & Short termco mplications & Ileus, Pulmonary embolism, Hysterectomy, Mendelson's Syndrome & $\overline{0.21224}$ \\
\hline & Psychological Issues & Post natal depression & 0.06435 \\
\hline \multirow{4}{*}{$\begin{array}{l}\text { Risks } \\
(0.291641)\end{array}$} & Death & Mortality & $\overline{0.67730}$ \\
\hline & Cosmetics Outcomes & Caesarean scaring, episiotomy scare & 0.16291 \\
\hline & Poor Obstetric outcomes & $\begin{array}{l}\text { Placental pathologies: placenta previa, accreta, placental abruption, } \\
\text { infertility, ectopic or still births, fetal mal for mations, pre termbirth, }\end{array}$ & 0.01534 \\
\hline & Long termco mplications & $\begin{array}{l}\text { Adhesion formation, Intestinal obstruction, Bladder injury, Uterine } \\
\text { rupture in subsequent pregnancies, Fecundity, Ectopic pregnancies, } \\
\text { Prolapse, Urinary and anal incontinence }\end{array}$ & $\overline{0.14445}$ \\
\hline
\end{tabular}

\section{Sensitivity Analysis}

The following sensitivity analysis graphs were generated with the used of the Super Decisions software. Based on the graphs it's evident that, when all merits increase the preferred alternative does not change.

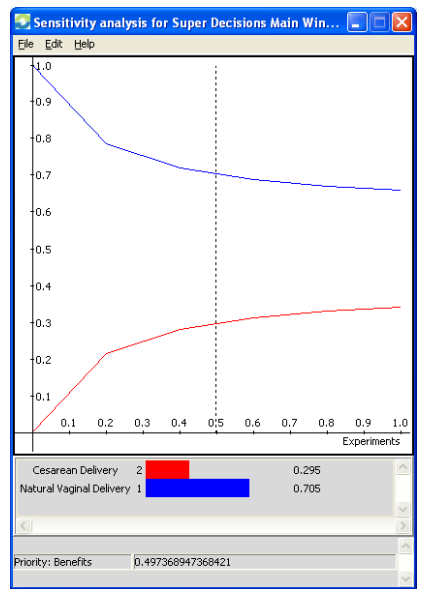

Figure 6: Sensitivity Analy sis for Benefits

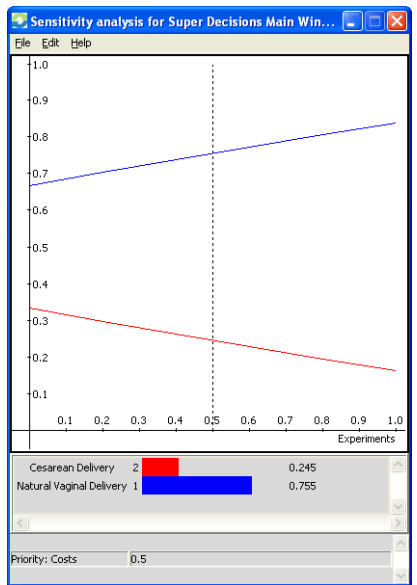

Figure 8: Sensitivity Analy sis for Costs

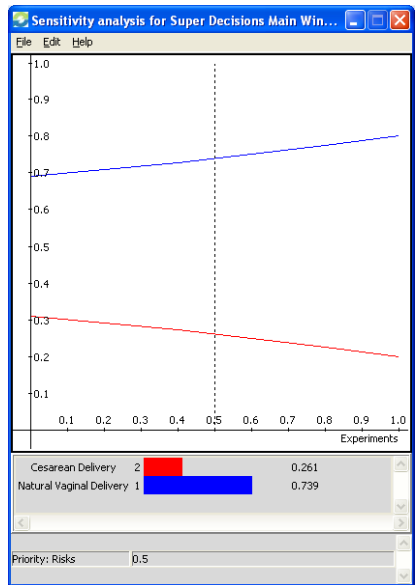

Figure 7: Sensitivity Analysis for Risks

\section{Conclusion}

The results of the research suggest that, the preferred alternative weighing benefits against costs and risks is Normal Vaginal Delivery at a rate of $72 \%$. This is mainly due to the higher benefits which compensate the costs and risks of normal delivery. The results of the research are consistent with Begam et al (2009) which also conclude that the NVD is preferred due to more benefits than CS and less cost compared to CS. The research also yielded that the level of sophistication, although highly emphasised in literature, was found to be less significant. This might be due to the fact that the research was based on perception of mostly male doctors and not female patients. However, if it was compared by the expecting mothers, there would have been a probability for the results to change. Therefore, future research to explore the views of mothers and other stakeholders engaged in the decision is recommended. The results of this research could however be used by Health policy makers to regulate the selection of caesarean sections, making it only available for mothers who are categorized as high risks or complicated pregnancies. It is also recommended to create awareness among school girls, in the form of media campaigns as well as seminars and workshops about the issue moreover stressing on the benefits received from NVD and the risks of CS.

\section{REFERENCES}


Saaty, T. (2010). Principia Mathematica Decemendi. Pittsburgh: RWS Publications.

Saaty, T., \& Ozdemir, M. (2005). The Encyclicon: A Dictionary of Decisions with Dependence and Feedback Based on The Analytical Network Process. Pittsburgh: RWSPublications.

Shang, J., T jader, Y., \& Ding, Y. (2004). A Unified Framework for Multicriteria Evaluation of Transportation Projects. IEEE TRANSACTIONS ON ENGINEERING MANAGEMENT, 51 (3).

BUHIMSCHI, C., \& BUHIMSCHI, I. (2006). Advantages of Vaginal Delivery. CLINICAL OBSTETRICS AND GYNECOLOGY , 49, 167-183.

Hamilton, B., Martin, J., \& Ventura, S. (2010). Births: Preliminary Data for 2009. CDC.

Betrán , A., Merialdi, M., Lauer, J., Bing-Shun, W., Thomas, J., Van Look, P., et al. (2007). Rates of caesarean section: analysis of global, regional and national est imates. Paediatric and Perinatal Epidemiology, 21 (2), 98-113.

Khan , A., \& Zaman, S. (2010). Costs of vaginal delivery and Caesarean section at a tertiary level public hospital in Islamabad, Pakistan. $B M C$ Pregnancy and Childbirth.

Menacker, F. (2005). Trends in Cesarean Rates for First Births andRepeat Cesarean Rates for Low-Risk Women:United States, 1990-2003. CDC.

Randolph, A., Washington, E., \& Prober, C. (1993). Cesarean Delivery for Women Presenting With Genital Herpes Lesions. The Joumal of the American Medical Association, 77-82.

Siddal, J., Street, P., Ablet, J., Selinger, M., \& Allott, H. (2005). Information for women considering an elective Caesarean section. Retrieved February 20, 201 1, from http://www.royalberkshire.nhs.uk/PDF/elective_caesarean_section\%202008.pdf

The Associated Press. (2010). C-section rates around globe at 'epidemic' levels. Retrieved February 20, 2011, from http://www.msnbc.msn.com/id/34826186/ns/health-pregnancy/

Begum , B., Zaman, R., Rahman , A., Rahaman, M., Uddin , M., Hafiz, R., et al. (2009). Comparison of risks and benefits of normal vaginal and caesarian section deliveries in a public tertiary hospital in Bangladesh. Mymensingh Medical Journal, 12-14.

Durham, J. (2010c). Understanding the Cesarean Epidemic. Retrieved February 20, 2011, from htt $: / /$ www.transitiontoparenthood.com/ttp/foreducat ors/csepidemic.ht m

Bergero, V. (2007). THE ETHICS OF CESAREAN SECTION ON MATERNAL REQUEST:A FEMINIST CRITIQUE OF THE AMERICAN COLLEGE OF OBSTETRICIANS AND GYNECOLOGISTS' POSITION ONPATIENT - CHOICE SURGERY. Bioethics, 21, 478-487.

Central Inteligence Agency. (2011). Retrieved February 20, 2011, from https://www.cia.gov/library/publications/the-world-factbook/geos/ce.html

Childbirth Connection. (2010). Why does the cesarean rete keep going on? Retrieved February 20, 2011, from http://www.childbirthconnection.org/pdfs/rising-cesarean-section-rate.pdf

Childbirth Organization. (ND). Cesarean Fact Sheet. Retrieved February 20, 2011, from $\mathrm{http}: / /$ birthingalternatives.com/Resources/Cesarean/All\%20Abt\%20Cesarian.pdf

Department of Census and Stat istics - Sri Lanka. (2010). Retrieved February 20, 2011, from http :/www.statistics.gov.lk/

Gilbert, A., Benjamin, A., \& Abenhaim, H. (2010). Does education level influence the decision to undergo elective repeat caesarean section among women with a previous caesarean section? Joumal of Obstetrics and Gynaecology Canada, 942-947.

Gunasekera, P., Wijesinghe, P., \& Goonewardene, I. (2001). The caesarean section rate is rising. Ceylon Medical Journal.

Homebirth Network SA. (2011c). Birth is not an illness: Fortelesa Decleration - Recommendations from World Health Organization 1985. Retrieved February 20, 201 1, from http://www.homebirthsa.org.au/PDF\%20Files/BirthNotIllness.pdf

Motherfriendly Organization. (2010). The Risks of Cesarean Section - A coaliation for inproving Matemity Services. Retrieved February 20 , 2011, from http://www.motherfriendly.org/pdf/TheRisksofCesareanSectionFebruary 2010.pdf

Mukherjee, S. (2006). Rising cesarean section rate. The Joumal of Obstetrics and Gynecology of India, 56, 298-300.

NICE. (2004). Caesarean Section.

Spaeth, T. (2010). The rise of cesarean section. The Joumal of Undergraduate Nursing Writing , 4 (1), 46-53.

Shearer, E. (1993). Cesarean Section: Medical benefits and costs. Social Science and Medicine, 37(10), 1223-1231.

Sunday Observer. (2007). C-sections, now expectantmothers' choice! Retrieved February 20, 2011, from http://www.sundayobserver.lk/2007/01/28/imp09.asp

Tollånes, M., Thompson, J., Daltveit , A., \& Irgens , L. (2007). Cesarean section and maternal education; secular trends in Norway, 1967-2004. Acta Obstetricia et Gynecologica Scandinavica, 840-848.

Ugwumadu, A. (2005). Does the Maxim “Once a Caesarean, Always a Caesarean” Still Hold True? PLOS Medicine.

United Nations Population Fund Sri Lanka. (2009). 15th International Conference of Populationand Development. 